\title{
Healthcare Professional Protective Mask for COVID-19
}

\author{
V Parthasarathi
}

Department of Fashion Technology, PSG College of Technology, Peelamedu, Coimbatore - 641 004, India

To Cite this Article

V Parthasarathi, "Healthcare Professional Protective Mask for COVID-19", International Journal for Modern Trends in Science and Technology, 6(9S): 07-13, 2020.

Article Info

Received on 25-August-2020, Revised on 08-September-2020, Accepted on 12-September-2020, Published on 18-September-2020.

\section{ABSTRACT}

The World Health Organization's (WHO) guidelines regarding prevention and control of the COVID-19 outbreak recommends respiratory hygiene and the use of personal protective equipment. Three layered antiviral mask has been developed by combining polyester nonwoven as an outer, Polytetrafluroethylene (PTFE) as a middle and viscose nonwoven as an inner layer. All three layers of fabrics were fused as laminate to develop the mask to protect healthcare professionals from Corona virus. All the surgical mask tests were performed to make compliance with global standards. Primarily viral penetration and bacterial filtration efficiency was performed according to ASTM standard F1671 and F2100 respectively.

Mean flow pore diameter of Single layer Polyester surgical mask, Dual layer of Polyester and PTFE film surgical mask, three layered surgical mask was 0.33, 0.30, 0.39 $\mu \mathrm{m}$. The developed three layered fabric with polyester as an outer layer, microporous PTFE film as a middle layer and viscose nonwoven fabric as an inner layer has passed the viral penetration test, which confirms that the mask has protection against Corona virus. Paired t-test analysis of the tensile strength in machine and cross directions shows that there is significant difference at $95 \%$ confidence interval.

Single layer polyester nonwoven surgical mask failed viral penetration test as the average pore diameter is $0.33 \mu \mathrm{m}$ which is more than size of $\Phi X 174$ bacteriophage virus as $0.2 \mu \mathrm{m}$ and in the absence of PTFE film. Dual and three layered surgical mask passed viral penetration analysis as it has smallest pore diameter is $0.16 \mu \mathrm{m}$ and $0.19 \mu \mathrm{m}$ respectively. PTFE film allows water vapour to pass through. In the current pathetic and demanding situation the three layered surgical mask was having barrier against Coronavirus which facilitate healthcare care professionals from cross-contamination and protecting them from current Pandemic.

KEYWORDS: Covid-19, tri-layered mask, protective mask, healthcare mask, face mask

\section{INTRODUCTION}

Coronavirus (Covid -19) is a great global threat which causes respiratory problems which may result fatal. Since COVID-19 is a disease spread by aerosol droplets from the airway of infected patients, it is declared as a pandemic by the World Health Organization on 11 March 2020. For tackling this COVID19 pandemic, efforts are taken to prevent transmission of virus to front-line health care workers who are taking counter measures to treat the affected persons. However, there is an immediate requirement of personal protective equipment (PPE). Increasing demand of one-time-use personal protective equipment (PPE) has become International concern [1]. 
In the current pandemic scenario, a lack in the supply of protective material such as protective facemasks for health care professionals can result in significant increase of disease. Preventing and avoid spreading of infection is the most important thing in the present Pandemic situation and subsequent period of re-structuring the normal life of public [2]. At most care should be taken to avoid spreading of the disease to the front-line health care workers by using personal protective equipment and to avoid contact with the infected patients [3].

As per Wuetal studies Coronavirus is mainly transmitted via respiratory droplets and can be transmitted between humans. Symptoms of the Corona infection are fever, cough, fatigue, headache, haemoptysis and diarrhoea. Increasing necessity of different universal facemask wearing policy scenarios, shortage of facemask would occur [4]. According to World Health Organization (WHO) guidelines, 3 layers protective material is essential for all healthcare providers. The Current Pandemic situations can induce a shortage of filtering face mask for healthcare professionals [5].

Dane and Schwartz reported that the fabric performance is changed when fabrics first come in contact with a fluid which may work together to reduce the barrier resistance of material to liquid penetration. It was expected that pre-wetting shall increase liquid penetration of fabrics [6].

Personal Protective Equipments should give protection barrier against the transmission of microorganisms and fluids in order to minimize risk of strike-through and for the patient's protection.

In the public's perception of healthcare professionals, uniforms play an important role. The professionalism and trustworthiness of practitioners are judged by patients based on the clothes the professionals wear. Socially constructed concepts of cleanliness that result in unachievable expectations may be reinforced by the colour and design of uniforms [8]. Diseases to their hosts are caused by infectious agents which are biological agents. In healthcare sector more infectious agents are present. The patients and healthcare workers are most likely sources of infectious agents and the most common susceptible hosts [9].

Association of Operating Room Nurses (2010) suggested that the fabrics used for gown and drapes must resist liquid transmission, abrasion and punctures and minimize passage of bacteria from non-sterile to sterile areas [10].Neely \& Maley (2000) studied the following five hospital textiles such as $100 \%$ cotton clothing, $100 \%$ cotton terry towel, Polyester cotton blend scrub suit, $100 \%$ polyester drape and $100 \%$ polypropylene splash aprons [11].Both fabric and non-fabric materials are used to make surgical scrubs. The study was aimed to observe whether there is scientific evidence that supports the practice of wearing scrubs in surgeries based on the materials they are made of [12].

Due to the prevalence of corona viruses in the patient population, the barrier efficacy of protective surgical gowns and mask have gained importance. Using standard laboratory conditions, which are different from the conditions encountered in the surgical area, most of the surgical gown fabrics are tested and categorized [13]. To apply both antimicrobial with flurochemical repellent finishes to surgical fabrics, a one-bath process was investigated by Wei huang and Karen. The repellent finishes are applied to the two nonwoven fabrics such as polypropylene spunbonded/meltblown/spunbonded fabric and a wood pulp/polyester spunlaced fabric [14].

The importance of protecting healthcare workers from body fluids has also been recognized. The front line health care workers who are responsible for controlling the surgical environment should have the technical, practical, consistent knowledge of evaluating the barrier properties of surgical apparel. There is no uniform code or guideline that defines the preferred method or methods of evaluation while many laboratories have, by necessity, agreed upon a limited number of test procedures to evaluate the liquid penetration resistance or repellency of a barrier material [15].In order to establish the final AAMI classification there are four tests that must be performed: Spray Impact Penetration Test; Hydrostatic Head Test; ASTM F1670 blood resistance; ASTM F1671 viral barrier testing. To determine, if the product is protective or non-protective the Spray Impact Test is performed. The level of protection from 1-3 is indicated by the Hydrostatic Pressure Test result. Finally the ASTM F1670 and ASTM F1671 are to be performed for those products that are required to be fully impervious [16].

Longer hospitalisation of patients with a healthcare associated infection and the extra treatments like surgery and antibiotics require extra costs. The hospital stay of patients with a healthcare-associated infection is estimated to be 
2.5 times longer than that of patients without such an infection and the cost of treatment is many times higher [17]. Both reusables and disposables are better in different environmental impacts. The factors to improve both reusables and disposable systems are difficult to assess as large scale studies of comfort, protection, or economics [18]. In accordance with the Occupational Health and Safety Administration (OSHA) guidelines for the appropriate use of personal protective equipment (PPE) are as follows. The employer shall provide suitable personal protective equipment such as face shields or masks, gloves, laboratory coats and eye protection and mouthpieces, pocket masks or other ventilation devices when there is occupational exposure, free of cost to the employee [19].

The most likely sources of infectious agents and also the most common susceptible hosts are patients and healthcare workers. Visitors and workers in healthcare may also be at risk of both infection and transmission. ${ }^{20}$ Chinese health authorities after detailed studies to characterise and control the disease came to a conclusion that the suspected disease affected people should be kept in isolation and to monitor them and their close contacts, collect clinical tested data from the infected patients and development of treatment procedures [21]. This research work aims to develop three layered fabric by combining polyester, polytetrafluoroethylene and viscose nonwoven. Analyze the suitability of these three layered fabric for antiviral surgical mask application to prevent from covid-19.

\section{METHODS}

Spun bond polyester nonwoven fabrics with basis weight of 25 grams per square meter (GSM) were obtained from mogul nonwoven industry, Turkey. The diameter of the individual filament was approximately 23 microns. The basis weight of the sourced viscose nonwoven was 25 GSM. The thickness of the polyester nonwoven fabric was $0.26 \mathrm{~mm}$. The pore size of polytetrafluroethylene (PTFE) film was $0.1 \mu \mathrm{m}$. For the development of three layered surgical mask polyester was the outer layer, polytetrafluoroethylene film was used as middle layer and inner layer as a viscose nonwoven.

Fabrics were characterized with weight and thickness following ASTM D 1777-64 Standard Method for Measuring Thickness of Textile Materials and ASTM D3776-85 standard method for Mass per unit area of a Fabric. The fabric characteristics of nonwoven fabrics are shown in Table 1.

Table 1 Fabric specifications

\begin{tabular}{lcc}
\hline Specifications & Polyester & Viscose \\
\hline $\begin{array}{l}\text { Areal density } \\
\left(\mathrm{g} / \mathrm{m}^{2}\right)\end{array}$ & 25 & 25 \\
Thickness $(\mathrm{mm})$ & 0.26 & 0.25 \\
$\begin{array}{l}\text { Individual } \\
\text { Filament } \\
\text { fineness }(\mu \mathrm{m})\end{array}$ & 0.8 & 6 \\
\hline
\end{tabular}

\section{Nonwoven Fabric Pore Size Characterisation}

The image system used consists of a WIRA XEC-T20 trinocular compound microscope and a Moticam CCD camera mounted on the top of the microscope for capturing images and a True vision image board installed in PC for digitizing the images. A nonwoven fabric was placed in the microscope and an objective of 400x magnification was selected to resolve images with a magnification about 473 pixels $/ \mathrm{mm}$ on the computer monitor. The pore size of the nonwoven fabric was also analysed using capillary flow porometer according to standard ASTM F 316. In porometry principle, the liquid reduces the free energy of the system by spontaneously filling the pores of the solid, when the liquid-solid interfacial free energy is less than the solid gas interfacial free energy. These liquids which are called as wetting liquids cannot spontaneously come out of pores.

\section{Development of surgical mask}

Three layers of fabrics such as polyester nonwoven as an outer layer, PTFE film as a middle layer and viscose nonwoven fabric as an inner layer were bonded together using a fusing machine at a temperature of $210^{\circ} \mathrm{C}$ with heated roller temperature of $240^{\circ}$ and roller pressure of 120 $\mathrm{N} / \mathrm{cm}^{2}$. Figure 1 shows the fragmentary top view of laminated fabric in accordance with present research work. 


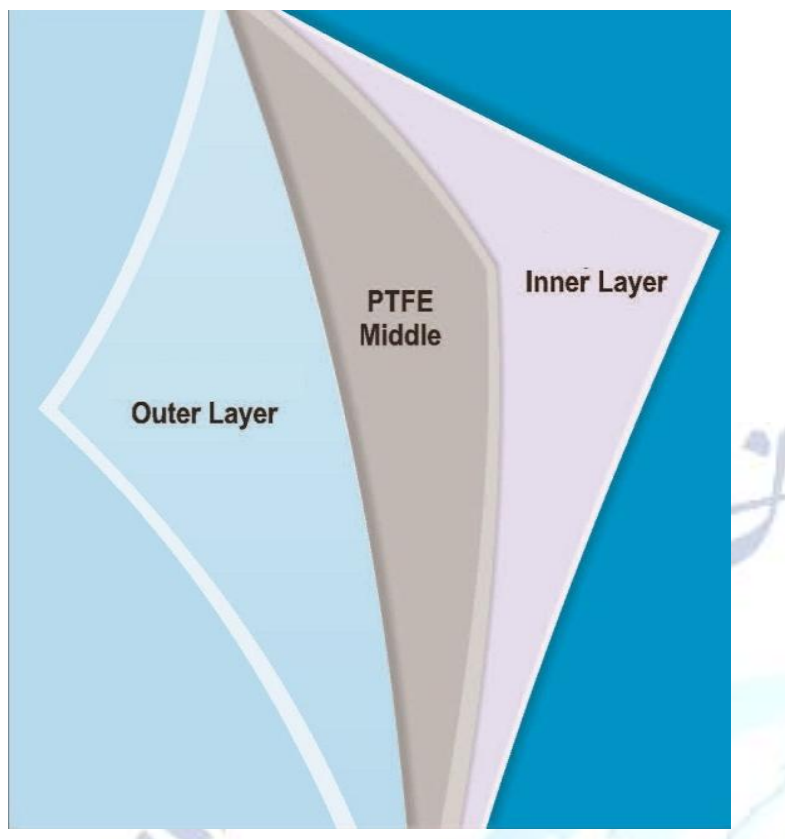

Figure 1 Three layered surgical mask fragmentary view

\section{TESTING METHODS OF SURGICAL} MASK

\section{Viral Penetration Test}

Viral penetration testing of surgical mask using ASTM F 1671 was carried out to investigate the antiviral property. The resistance capacity of the materials used in the Protective clothing is tested by ASTM F1671 test method for penetration by blood borne pathogens, using bacteriophage under the condition of continuous liquid contact. The test system has been designed for measuring penetration of surrogate microbe for hepatitis B virus (HBV), hepatitis $\mathrm{C}$ virus (HCV) and HIV. The protective clothing materials to be tested are intended to provide protection against blood, body fluids, droplets and other potentially infectious materials.

\section{Bacterial filtration efficiency}

Face masks are designed to provide protection against biological aerosols. The Bacterial Filtration Efficiency (BFE) test is performed on mask according to ASTM F2 100.

\section{Measurement of Tensile Strength and Elongation}

The Tensile strength ASTM D5034 grab test method was used for the determination of breaking load and elongation of tri-laminate fabrics since the procedures have been used extensively in the trade for acceptance testing. Tensile tests of the tri-laminate fabrics were performed using a Zwick Universal Testing Machine with a load cell of $10 \mathrm{kN}$ capacity. Nonwoven fabric strip was cut into the dimensions $100 \times 150 \mathrm{~mm}$. The gauge length was set $80 \mathrm{~mm}$ and each specimen was elongated at a crosshead speed of $50 \mathrm{~mm} / \mathrm{min}$.

\section{Measurement of Tearing Strength}

For the determination of tearing strength by the falling pendulum type apparatus, ASTM D1424 test method is used. This test method, using a falling-pendulum Elmendorf type apparatus, covers the determination of the force required to propagate a single-rip tear starting from a cut in a fabric.

\section{Measurement of Hydrostatic Resistance}

To measure the resistance of a fabric to the penetration of water under hydrostatic pressure, the AATCC 127 method was used. Three specimens of fabric were diagonally taken across the width of the fabric to represent the material. The specimens were cut into $200 \times 200 \mathrm{~mm}$ swatches to allow proper clamping. Hydrostatic pressure was applied on one surface of the test specimen, increasing at a constant rate, until three points of leakage appear on its other surface.

At the top of inclined stand one side of the specimen was clamped with the spring clamp and to the free end of sample another clamp of 0.4536 $\mathrm{kg}$ was fixed. In the funnel of the tester $500 \mathrm{ml}$ of distilled water was poured and onto the specimen it was allowed to spray from a height of $60 \mathrm{~cm}$. Water pressure is applied on a test specimen mounted under orifice of a conical well, increasing at a constant rate until three leakage points appear on its surface.

\section{Measurement of Moisture Vapour Transfer Rate (MVTR)}

To test the characteristics of the breathability of fabrics, moisture vapor transfer rate measurement is made. To evaluate the MVTR of three layered nonwoven mask fabric, evaporative dish method following the British Standard BS 7209:1990 was used. The testing was carried out at standard laboratory conditions of $65 \pm 2 \%$ relative humidity and $20 \pm 2^{\circ} \mathrm{C}$ temperature (McCullough et al 2003). Individual dish ring assembly and MVTR equipment as recommended by BS 7209:1990 method

\section{RESULTS AND DISCUSSION}

The smallest pore diameter, mean flow pore diameter and bubble point diameter of surgical mask are reported in the Table 2. Mean flow pore diameter of three layered surgical mask is higher than polypropylene nonwoven mask due to 
polyester nonwoven fabric comprises coarser individual filament fineness and more void of viscose nonwoven than polypropylene fabric. The increase in mean flow pore diameter has increased the moisture vapour permeability. The pore size of polyester nonwoven is $0.33 \mu \mathrm{m}$. Mean flow pore diameter of the dual laminated polyester nonwoven with PTFE surgical mask is reduced due to the presence of stretched PTFE polymer matrix.

Table 2. Pore Size of Single, Dual and three layered surgical mask

\begin{tabular}{|c|c|c|c|}
\hline Surgical Gown & $\begin{array}{l}\text { Smalles } \\
t \quad \text { Pore } \\
\text { Diamet } \\
\text { er }(\mu \mathrm{m})\end{array}$ & $\begin{array}{l}\text { Mean } \\
\text { Flow } \\
\text { Pore } \\
\text { Diamet } \\
\text { er }(\mu \mathrm{m})\end{array}$ & $\begin{array}{l}\text { Bubble } \\
\text { Point } \\
\text { Diamet } \\
\text { er }(\mu \mathrm{m})\end{array}$ \\
\hline $\begin{array}{l}\text { Single layer Polyester } \\
\text { surgical mask }\end{array}$ & 0.31 & 0.33 & 0.52 \\
\hline $\begin{array}{l}\text { Dual layer of Polyester } \\
\text { and PTFE film surgical } \\
\text { mask }\end{array}$ & 0.16 & 0.30 & 8 \\
\hline $\begin{array}{l}\text { Three layered surgical } \\
\text { mask } \\
\text { (Polyester/PTFE/visco } \\
\text { se) }\end{array}$ & 0.19 & 0.39 & 0.44 \\
\hline
\end{tabular}

Table 3. Results of (Polyester/PTFE/Viscose) Surgical Mask

\begin{tabular}{|c|c|c|c|c|c|c|c|}
\hline (2) & 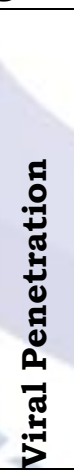 & 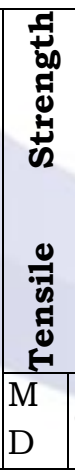 & $\frac{\overline{2}}{\mathrm{CD}}$ & $\begin{array}{l} \\
\mathrm{M} \\
\mathrm{D} \\
\end{array}$ & $\begin{array}{l}\text { C } \\
\text { D }\end{array}$ & 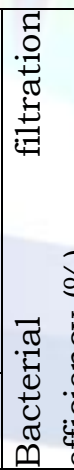 & 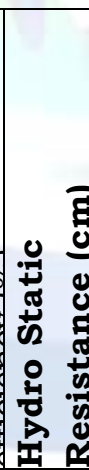 \\
\hline $\begin{array}{l}\text { Single layer Polyester } \\
\text { surgical Mask }\end{array}$ & Fail & 68 & 41 & 5 & 1. & $\begin{array}{l}73 . \\
5\end{array}$ & 22 \\
\hline $\begin{array}{l}\text { Dual layer of } \\
\text { Polyester and PTFE } \\
\text { film surgical mask }\end{array}$ & $\begin{array}{l}\text { Pas } \\
\text { s }\end{array}$ & $\begin{array}{l}10 \\
5\end{array}$ & 62 & 7 & 2 & $\begin{array}{l}98 \\
7\end{array}$ & 31 \\
\hline $\begin{array}{l}\text { Three layered } \\
\text { surgical mask } \\
\text { (Polyester/PTFE/visc } \\
\text { ose) }\end{array}$ & $\begin{array}{l}\text { Pas } \\
\text { s }\end{array}$ & & $\begin{array}{l}10 \\
8\end{array}$ & 8 & 3 & $\begin{array}{l}99 . \\
4\end{array}$ & 37.6 \\
\hline
\end{tabular}

The Table 3 shows the results of mechanical properties of single, dual and three layered surgical mask. The developed three layered fabric with polyester as an outer layer, microporous PTFE film as a middle layer and viscose nonwoven fabric as an inner layer, named as PET 1 mask, has passed the viral penetration test, which confirms that the mask has protection against the hepatitis $\mathrm{B}$ and hepatitis C, human Immunodeficiency viruses, corona virus and surrogate $\Phi$ X174 bacteriophage.

In single layer mask one correlate with level 1 mask protection, where as dual, three layered mask having high level of protection with bacterial filtration efficiency of greater than $95 \%$.

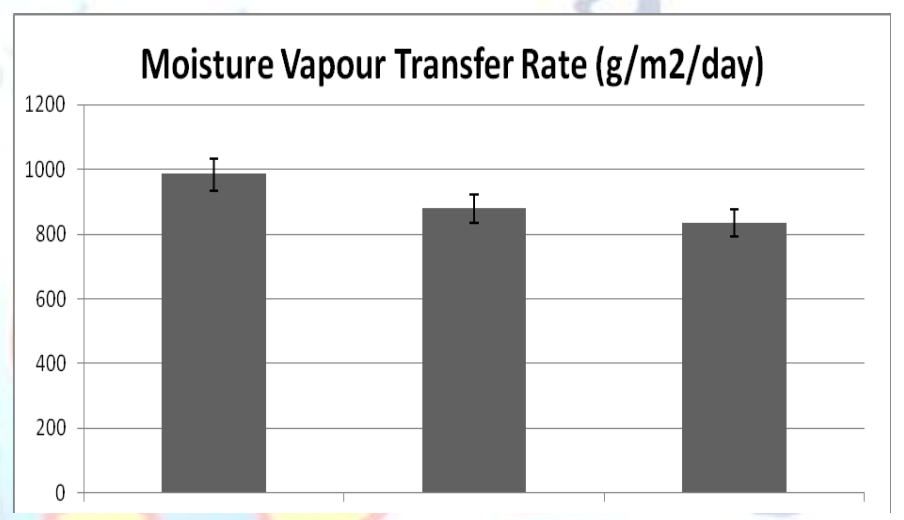

Figure 2 water vapour permeability single, dual, three layered mask

It is observed from Figure 2 that while laminating with PTFE, polyester and viscose nonwoven fabrics, the water vapour permeability reduces as the layer increases. The moisture vapour permeability of single layer polyester gown is 985 $\mathrm{g} / \mathrm{m}^{2} /$ day which is better than single layer polypropylene because the pore size of polyester is $0.33 \mu \mathrm{m}$ which is higher than polypropylene pore size of $0.29 \mu \mathrm{m}$.

Single layer polyester nonwoven surgical masks failed in viral penetration analysis because the pore size of polyester was $0.33 \mu \mathrm{m}$ and the thickness of polyester nonwoven was $0.26 \mathrm{~mm}$. Single layer polyester nonwoven surgical mask failed viral penetration test as the average pore diameter is $0.33 \mu \mathrm{m}$ which is more than size of $\Phi \times 174$ bacteriophage virus as $0.2 \mu \mathrm{m}$ and in the absence of PTFE film. Dual layer of Polyester and PTFE film surgical mask passed the viral penetration analysis, as the PTFE has $0.1 \mu \mathrm{m}$ porosity through which viruses cannot penetrate.

Hence it is fused with an outer polyester layer to give liquid barrier protection. Single layer polyester nonwoven surgical mask failed viral penetration 
test as the average pore diameter is $0.33 \mu \mathrm{m}$ which is more than size of virus and in the absence of PTFE film.

Dual and three layered PET 1 surgical mask passed viral penetration analysis as it has smallest pore diameter is $0.16 \mu \mathrm{m}$ and $0.19 \mu \mathrm{m}$ respectively. Polyester nonwoven fabric is used as an outer layer because it is hydrophobic fibre and does not attract water. It is also non-polar and hence repels blood fluids.

Higher surface area of the microfibers in the spunbond polyester nonwoven fabric which is the outer layer, acts as a liquid barrier.

The tensile strength of the PET 1 three layered fabric in machine direction (MD) is $190 \mathrm{~N}$ which is greater than the cross direction (CD) of the sample which is $108 \mathrm{~N}$. Paired t-test analysis of the tensile strength in machine and cross directions shows that there is significant difference at $95 \%$ confidence interval. The tearing strength of the three layered mask fabric in direction I and II was $8 \mathrm{~N}$ and $3 \mathrm{~N}$ respectively.

The tearing strength of the fabric in the direction I is more, due to the laying of polyester fibre in the machine direction during extrusion. In hydro static resistance, it is observed that the weight of water penetrating through the fabric during impact penetration test decreases as the weight of fabric increases. The results are statistically significant for single layer and PET 1 three layered mask at 95\% confidence level.

The PET 1 mask moisture vapor permeability test result was $834 \mathrm{~g} / \mathrm{m}^{2} /$ day which also confirm the mask requirements. Spunlaced viscose nonwoven absorption influences the better moisture transfer. PTFE film allows water vapour to pass through. The water vapour from perspiration be transmitted from inside to outside so that under do not become wet and a natural evaporative cooling effect can be achieved.

Though the addition of viscose nonwoven as the inner layer increases moisture vapour permeability and drying rate of the surgical mask.

The developed three layered mask can be used for protecting healthcare people from the risk of Covid-19 and high risk of exposure to fluid amount, splash and pressure on mask in medical procedures.

The surgical mask has better moisture vapour transfer rate as compared to other commercial polypropylene mask. So that wearer can use it with comfort as the inner layer gives soft touch to wearer's skin increasing the property of comfort to the user.
In the current challenging situation the mask having Coronavirus barrier property is also established in this surgical mask thereby reducing cross-contamination between medical staff and patients.

\section{REFERENCES}

[1] Rowan N J, Laffey J G (2020) Challenges and solutions for addressing critical shortage of supply chain for personal and protective equipment ( $\mathrm{PPE}$ ) arising from Coronavirus disease (COVID19) pandemic - Case study from the Republic of Ireland, Science of the Total Environment ;Doi.org/10.1016/j.scitotenv.2020.138532

[2] Swennen GRJ, et al. (2020) Custom-made 3D-printed face masks in case of pandemic crisis situations with a lack of commercially available $\mathrm{FFP} 2 / 3$ masks, Int $\mathrm{J}$ Oral Maxillofac Surg.

[3] Akladios C et al. (2020) Recommendations for the surgical management of gynecological cancers during the COVID-19 pandemic - FRANCOGYN group for the CNGOF, J Gynecol Obstet Hum Reprod ; Doi.org/10.1016/j.jogoh.2020.101729

[4] Wuetal (2020) Facemask shortage and the novel coronavirus disease (COVID-19) outbreak, Reflections on public health measures, EClinical Medicine ; Doi.org/10.1016/j.eclinm.2020.100329

[5] Swennen GRJ, et al.(2020) Custom-made 3D-printed face masks in case of pandemic crisis situations with a lack of commercially available FFP2/3 masks, Int $\mathrm{J}$ Oral Maxillofac Surg; Doi.org/10.1016/j.ijom.2020.03.015

[6] 6.Dane, JH, Schwartz, P (2005) Effect of Liquid characteristics on the wetting, capillary migration and retention properties of fibrous polymer networks - Part 2, Journal of Applied Polymer Science ; 98: 384-390.

[7] Mews, P (2009) Establish and maintain the sterile field Competency for safe patient care during operative and invasive procedures, Denver ;1: 240-249

[8] Loveday, HP, Wilson, JA, Hoffman, PN, Pratt, RJ (2007) Public perception and the social and microbiological significance of uniforms in the prevention and control of healthcare-associated infections: an evidence review, British Journal of Infection Control , 8: 10-21.

[9] Lin, H, He, N, Su, M, Feng, J, Chen, L, Gao, M (2011) Herpes simplex virus infections among rural residents in eastern China', BMC Infectious Diseases ; 11: 1-6.

[10] Association of Operating Room Nurses (AORN) (2010) Recommended practices: Protective barrier materials for surgical gowns and drapes, AORN Journal ; 55:832-835.

[11] Neely, AN, Maley, MP (2000) Survival of Enterococci and Staphylococci on hospital Fabrics and Plastics, Journal of Clinical Microbiology ; 38:724-726.

[12] Juliane Cristina Burgatti \& Rubia Aparecida Lacerda (2009) Systematic review of surgical gowns in the control of contamination/ surgical site infection, Review Enferm ; 43:229-236.

[13] Ducel, G, Fabry, J, Nicolle, L (2002) Prevention of hospital acquired infections, World Health Organisation, France

[14] Wei Huang \& Karen Leonas (2000) Evaluating a one-bath process for imparting Antibacterial and repellency to Nonwoven surgical gown Fabrics, Textile Research Journal ; 70: 774-782.

[15] Belkin, NL 2002, Barrier Surgical Gown and drapes: Just How necessary are they, Textile Rental , 1:. 66-73. 
[16] Association for the Advancement of Medical Instrumentation (AAMI) (2005), 'Selection and use of Protective apparel and Surgical drapes in healthcare facilities, AAMI Technical Information report ; 1:pp. 12-24.

[17] Okeke, IN, Laxminarayan, R, Bhutta, ZA, Duse, AG, Jenkins, P, Obrien, TF 2005, Antimicrobial resistance in developing countries. Part I: recent trends and current status, The Lancet Infectious Diseases ; 5: 481-493.

[18] Fung, W (2002) Coated and Laminated Textiles, Wood Head Publishing, England .

[19] Johnson, L, Schultze, D (2000) Breathable TPE Films for Medical Applications, AORN Journal ; 10: 50-53.

[20] Lin, H, He, N, Su, M, Feng, J, Chen, L, Gao, M 2(2011) Herpes simplex virus infections among rural residents in eastern China', BMC Infectious Diseases ; 11: 1-6.

[21] Chen Wang, Peter W Horby, Frederick G Hayden, George F Gao (2020) A novel coronavirus outbreak of global health concern, olume 395, ISSUE 10223, The Lancet, Feb ;. Doi.org/10.1016/ S0140-6736(20)30185-9

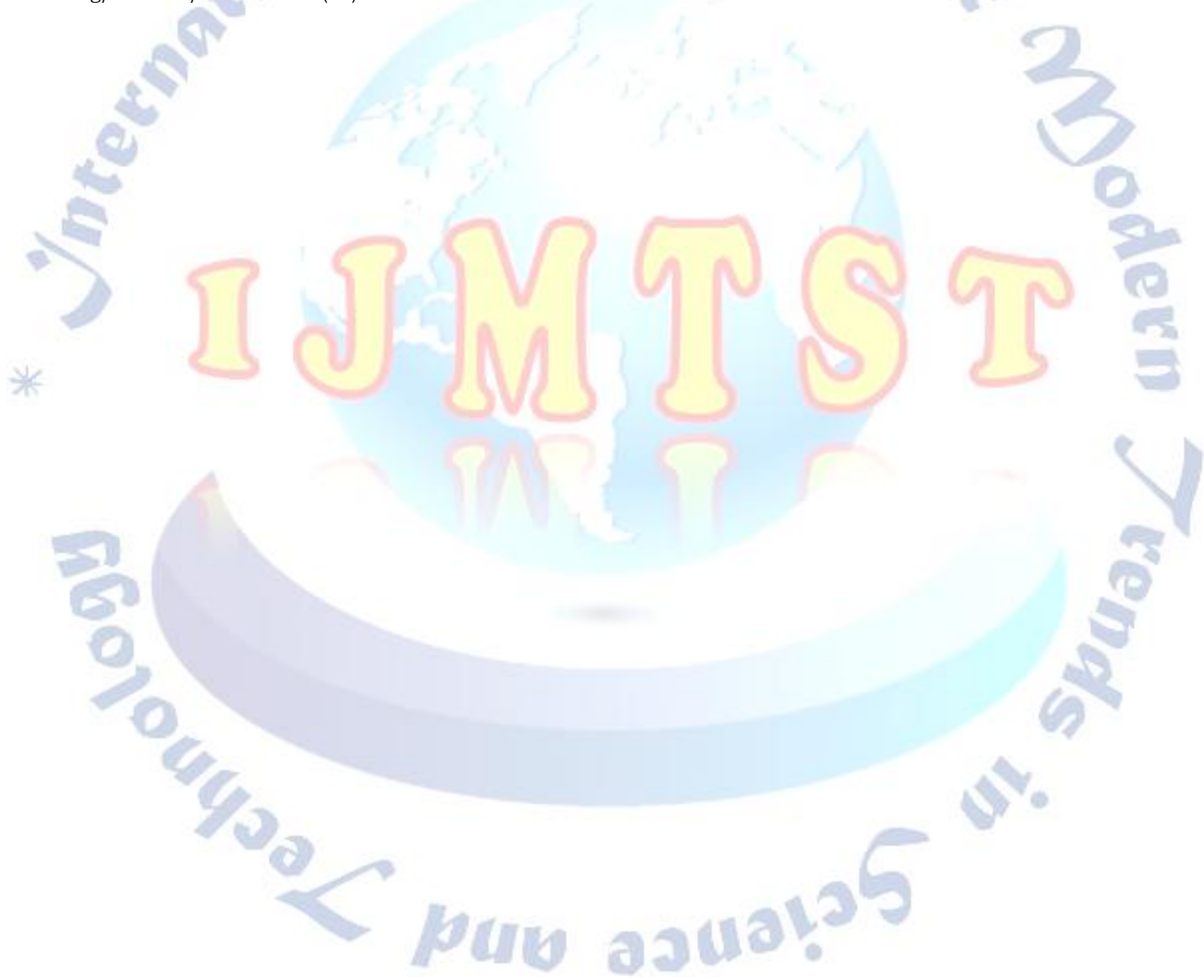

